\title{
PENGARUH PEMBINAAN, PENGETAHUAN MANAJERIAL, DAN KOMUNIKASI INTERPERSONAL TERHADAP PENGAMBILAN KEPUTUSAN KEPALA SEKOLAH DASAR (SD) NEGERI DI TANJUNG PRIOK
}

\author{
Entju Surjadi
}

\begin{abstract}
The purpose of this research is to find out the effect of directing, manajerial knowledge and decision making of state principal elementary school inTanjung Priok, the Capital City Local Specially Province Jakarta. There are 40 unit analysis used as the sample whom are chosen randomly. There are five results found in this research: 1). There is positive direct effect of directing to the decision making; 2). There is positive direct effect of directing to the interpersonal communication; 3). There is positive direct effect of manajerial knowledge to the decision making; 4). There is positive direct effect of manajerial knowledge to the interpersonal communication; and 5). There is positive direct effect of interpersonal communication to the decisionmaking. There a good elementary school principal's decison making become the base in improving quality human resources.
\end{abstract} $\begin{array}{ll}\text { Keywords } & \text { :Directing, Manajerial knowledge, Interpersonal } \\ \text { Communication, Decision Making. }\end{array}$

\section{Pendahuluan}

Kehidupan suatu bangsa secara berkesinambungan memerlukan pembangunan di segala aspek kehidupan warganya. Oleh sebab itu pembangunan tidak dapat ditawar-tawar lagi. Untuk menunjang pembangunan diperlukan sumber daya. Setiap bangsa memiliki beragam sumber daya terutama sumber daya alam. Melimpahnya sumber daya alam yang dimiliki setiap bangsa, akan sia-sia tanpa adanya sumber daya manusia untuk mengolahnya. Agar mampu mengolah dan mengelola sumber daya alam sehingga dapat digunakan untuk kesejahteraan masyarakat sebagai tujuan akhir dari pembangunan itu sendiri, maka salah satu bentuk pembangunan sumber daya manusia adalah pendidikan.

Sumber daya manusia memegang peranan yang sangat penting karena manusia merupakan penggerak terhadap sumber daya lainnya. Oleh sebab itu peranan sumber daya manusia dalam pembangunan balk dari segi kuantitas maupun kualitas perlu diperhatikan. Dengan kuantitas yaitu merupakan jumlah sumber daya manusia,sedangkan kualitas menyangkut mutu sumber daya manusia berupa kemampuan fisik maupun kemampuan non fisik. Meningkatkan kualitas fisik dapat dilakukan dengan pemberian gizi, sedangkanuntuk meningkatkan kualitas non fisik dilakukan melalui pendidikan, pendidikan dan pelatihan.

Lokasi Tanjung Priok dengan pantai Laut Jawa dengan suhu yang panas berbeda dengan wilayah lainnya. Keadaan penduduk juga pluralisme yang datang dari seluruh penjuru Indonesia. Keadaan keamanan Jakarta Utara rawan dengan kejahatan. Di sisi lain Daerah Khusus Ibukota (DKI) Jakarta merupakan tolok ukur keberhasilan pengelolaan pendidikan 
terhadap daerah lainnya. Keadaan ini akan mempengaruhi karakteristik manusia dalam mengelola organisasi sekolah termasuk juga siswa dalam mengikuti proses pembelajaran.

Sejalan dengan otonomi daerah, Undang-undang Nomor 32 Tahun 2004, Pasal 13 dan 14, menetapkan bahwa penyelenggaraan pendidikan menjadi salah satu urns an wajib yang menjadi kewenangan pemerintah daerah, maka kinerja kepala sekolah mengalami tantangan.

\section{Identifikasi Masalah}

Banyak variabel yang mempengaruhi pengambilan keputusan antara lain motivasi kerja, budaya organisasi, kepuasan kerja, struktur organisasi, manajemen mutu, sarana dan prasarana, kepemimpinan, kemampuan manajerial dan lain sebagainya.

\section{Pembatasan Masalah}

Keterbatasan sumber daya, waktu, dan biaya. Kurangnya kemampuan peneliti untuk meneliti variabel lainnya. Pertimbangan lainnya, agarpeneliti dapat menganalisis, mengkaji lebih tajam dan mendalam variabel yang diteliti.

\section{Perumusan Masalah}

Dari identifikasi masalah, maka dapat dibuat perumusan masalah sebagai berikut:

1. Apakahpembinaanberpengaruh langsungterhadappengambilan keputusan?

2. Apakah pembinaan berpengaruh langsung terhadap komunikasi interpersonal?

3. Apakah pengetahuan manajerial berpengaruh langsung terhadap pengambilan keputusan?

4. Apakah pengetahuan manajerial berpengaruh langsung terhadap komunikasi interpersonal?

5. Apakah komunikasi interpersonal berpengaruh langsung terhadap pengambilan keputusan?
6. Apakah pembinaan berpengaruh terhadap pengambilan keputusan melalui komunikasi interpersonal?

7. Apakah pengetahuan manajerial berpengaruh terhadap pengambilan keputusan melalui komunikasi interpersonal?

\section{Deskripsi Teoretik}

\section{Pengambilan Keputusan}

Menurut Jerald Greenberg, Robert A. Baron (2008: 380) mengatakan pengambilan keputusan merupakan proses pembuatan keputusan atas beberapa alternatif (decision making the process of making choice from among severalalternatives). Pada hakekatnya memilih alternatif terbaik dari beberapa alternatif yang tersedia. Untuk itu dibuat pedoman mengenai masalah yang ada. Kedudukan pengambil keputusan disesuaikan pada tingkat hirarki masingmasing.

Selanjutnya menurut Herbet A. Simon (1997: 5) mengatakan, "Semua keputusan adalah hal kompromi. Alternatif yang akhirnya dipilih tidak pernah lengkap atau pencapaian sasaran dengan sempurna, tetapi pemecahan yang paling balk" ("All decision is a matter of compromise" The alternative that is finally selected never permits a complete or perfect achievement of objectives, but is merely the best solution). Setiap keputusan tidak dapat memuaskan semua orang, diperlukan demokrasi di antara sesama anggota organisasi dan umpan batik (feedback) sebagai bahan evaluasi untuk perbaikan.

Menurut James A. F. Stoner, R. Edward Freeman (1992: 248) mengatakan, pengambilan keputusan merupakan pengenalan dan pemilihan tindakan untuk memecahkan masalah khusus (decision making the proses of identifying and selecting a course of action to solve a specific problem). Unsur dalam definisi ini yaitu proses pengenalan, pemilihan, tindakan, masalah. Dalam 
proses belajar mengajar, kepala sekolah menghadapi kegiatan rutin dan tidak rutin. Dalam menjalankan kegiatan rutin pengambilan keputusan dibuat sesuai dengan perkembangan proses belajar mengajar pada setiap tahun ajaran. Sedangkan kegiatan tidak rutin, adalah masalah khusus yang dapat terjadi secara setiap saat, memerlukan pengenalan dan pemilihan tindakan untuk memecahkannya.

Kajian teori di atas, maka dibuat sintesis, pengambilan keputusan adalah tindakan pimpinan dalam memilih alternatif yang terbaik setelah mempertimbangkan faktor intern dan ekstern guna memecahkan masalah dalam rangka mencapai tujuan organisasi.

\section{Pembinaan}

Menurut John M. Ivancevich (2007: 394), mengatakan pembinaan mempersiapkan individu untuk ke depan. Pemusatan pembinaan pada pembelajaran dan pembinaan pribadi (directing prepares individuals for the future. It focuseson learning and personal development). Kepala sekolah dibekali dengan keahlian, pengembangan dan berbagai informasi dalam mewujudkan visi dan misi pendidikan, sehingga dapat memberikan sumbangan positif dalam organisasi.

Menurut Harold Koontz, Cyril O'Donnell, Heinz Weihrich (1984: 438), mengatakan pembinaan manajer mengarahkan untuk membuat kemajuan manajer dalam pembelajaran bagaimana mengelola (manager directing to refer to the progress a manager makes in learning how to manage). Guru yang diangkat sebagai kepala sekolah adalah profesional dalam bidangnya, sehingga diharapkan secara berkesinambungan meningkatkan pengetahuannya. Untuk itu diperlukan pembinaan agar dapat berkarir dan berprestasi dalam melakukan tugas dan tanggung jawabnya.

Menurut Newstrom dan Davis (2002: 13), mengatakan pendekatan sumber daya manusia adalah pengembangan. Pendekatan mengenai pertumbuhan dan pengembangan orang terhadap tingkat kemampuan, daya cipta dan penyelesaian yang lebih tinggi, karena orang adalah pusat sumber daya dalam sesuatu organisasi dan sosial (the human resources approach is directing. It is concerned with the growth and development of people toward higher levels of competency, creativity, and fulfillment, because people are the central resource in any organization and any society). Orang atau masyarakat di dalam organisasi, baik lembaga sosial memerlukan kemampuan, keahlian, daya cipta agar dapat memajukan kehidupan baik sebagai individu maupun kelompok. Kepala sekolah tidak terlepas dari tugas pokok dan fungsinya, setiap hari berhadapan dengan sumber daya manusia yaitu guru dan siswa. Berbagai terobosan pengembangan dilakukan oleh pemerintah terhadap guru dan kepala sekolah antara lain, melalui pendidikan dan pelatihan, seminar, penataran, workshop, lokakarya dan lain sebagainya yang bertujuan agar dapat memberikan pelayanan prima.

Kajian teori di atas, maka dapat dibuat sintesis, pembinaan profesional adalah tindakan pemberian bantuan untuk meningkatkan kemampuan dalam melaksanakan tugas yang berdampak positif terhadap proses belajar mengajar.

\section{Pengetahuan Manajerial.}

Menurut Paul Hersey, Kenneth $\mathrm{H}$. Blanchard, Dewey E. Johnson (2008:32) mengatakan, kemampuan berkenaan dengan pengetahuan, pengikut-pengikut, pengalaman, dan keahlian - kemampuan melengkapi keberhasilan tugas khusus (abilityrefers to the follower's knowledge, experimence, and skill - the ability to complete the specific task successfully). Individu tidak mempunyai kemampuan yang universal. Setiap individu mempunyai kelebihan dan kekurangan dan dapat berubah-ubah. Perubahan pengalaman diperoleh dari proses belajar saat 
pelaksanaan tugasnya baik langsung maupun tidak langsung. Pengalaman berbeda dapat diakibatkan faktor pendidikan, tingkat inteligensi, keahlian, keterampilan, serta situasi kerja yang dihadapi.

Menurut Stephen P. Robbins and Timothy A. Judge, (2007: 42) mengatakan, berkenaan dengan kapasitas individu untuk melaksanakan bermacammacam tugas-tugas dalam suatu jabatan (refers to an individual's capacity to perform the various tasks in a job). Selanjutnya dikatakan bahwa secara keseluruhan kemampuan dibangun dari dua faktor yaitu kecerdasan (intellectual) dan pisik (physical). Kapasitas yang dimiliki kepala sekolah berupa pengetahuandalam mengelola tugas dan tanggung jawabnya. Pengetahuan berupa kecerdasan diperoleh dari pendidikan dan juga pengalaman.Pisik dilakukan melalui pemberian gizi.

Menurut Jennifer M. George and Garreth R. Jones (2005: 53) mengatakan kemampuan mental atau pisik melakukan sesuatu (ability, themental or physical to do something). Menurut Jerald Greenberg and Robert A. Baron (2008: 153) mengatakan kemampuan mental dan pisik untuk melaksanakan bermacam-macam tugas-tugas (abilities mental and physical capacities to perform various tasks). Sedangkan James L. Gibson et., al., (2006:96) mengatakan, suatu kemampuan adalahsifat (pembawaan lahir atau dipelajari) mental atau pisik yang membolehkan seseorang melakukan sesuatu (an ability is a trait (innate or learned) that permints a person to do something mental orphysical). Definisi yang singkat mempunyai makna yang sangat luas, yang mengatakan bahwa terdapat dua unsur di dalam kemampuan manusia yaitu berupa mental dan pisik. Kemampuan mental ${ }^{-}$yaitu yang berhubungan dengan jiwa atau batin ataurohaniah. Sedangkan fisik menyangkut dua aspek yaitu aspek fisik dan non fisik. Fisik merupakan kemampuan badaniah sedangkan non fisikmerupakankemampuanberupa,penget ahuan,keahlian, keterampilan, kecerdasan, pengalaman dan lain sebagainya.

Kajian teori di atas, maka dibuat sintesis bahwa, pengetahuan manajerial adalah kemampuan memadukan ilmu pengetahuan dan seni dalam merencanakan, mengorganisasikan, menggerakkan dan mengawasi semua sumber days yang tersedia guns mencapai tujuan pendidikan yang efektif dan efisien.

\section{Komunikasi Interpersonal}

Dalam komunikasi interpesonal setiap orang memiliki cara dan gaya tersendiri seperti pernyataan James L. Gibson et. al (2003: 424) Gaya komunikasi antar pribadi menunjukkan bagaimana seorang individu lebih suka berhubungan dengan yang lain (interpesonalcommnunication style refers to how an individual prefers to relate to other). Komunikasi bisa terjadi secara efektif apabila komunikator dan komunikan memiliki kesamaan makna dan atau tujuan. Atas dasar hal tersebut komunikator dituntut memiliki kemampuan khusus untuk memahami kondisi komunikan balk teknis mempengaruhi maupun teknik menggunakan berbagai perangkat, sehingga komunikan memberi respon positif.

Sesuai dengan pendapatLuthans (1998: 474) bahwa komunikasi interpesonal merupakan proses psikologis yang menjadi dasar perubahan tingkah laku dan penekanan utamanya pada transfer informasi dari satu orang ke orang lainnya. Kutipan ini mengatakan bahwa komunikasi sebagai proses interaksi atau hubungan sating pengertian satu sama lain di antaramanusia. Interaksi antar individu maupun kelompok akan mengubah tingkah laku. Dalam kehidupan sosial, yang beragama budaya, akan menimbulkan beragam komunikasi. 
Selanjutnya menurut Leslie W. Rui dan Llyoyd L. Byars (1996: 47), proses komunikasi antar pribadi termasuk di dalamnya pengiriman dan penerimaan pesan balk verbal maupun nonverbal di antara dua orang. Senada dengan definisi ini menurut John R. Schermerhorn (1998:56), bahwa komunikasi antara pribadi merupakan proses dalam rangka mengirimkan dan menerima simbol atau melalui pesan yang terdapat di dalamnya supaya tercipta pengertian kedua belah pihak atau lebih. Komunikasi merupakan kegiatan yang terjadi antara dua orang, yaitu sebagai pengirim dan penerima, Komunikasi dapat dilakukan secara verbal dan nonverbal.

Kajian konsep dari berbagai ahli tersebut di atas, maka dapat dibuat sintesis bahwa komunikasi interpersonal adalah hubungan timbal batik antara dua orang atau lebih dalam penyampaian dan penerimaan pesan baik verbal maupun non verbal.

\section{Kerangka Berpikir}

1. Pembinaan dan Pengambilan
Keputusan
Pembinaan ini dilakukan antara lain untuk mengenal ruang lingkuporganisasi, bidang tugas, memahami peraturan, mengetahui prosedur kerja, prosedur dan proses kepangkatan, struktur organisasi. Untuk itu pembinaan dilakukan dalam bentuk penataran, seminar, pendidikan dan latihan (diktat), sehingga dapat meningkatkan pengetahuan pegawai dalam melaksanakan tugas dan tanggung jawabnya.

Menurut Jason A. Colquitt (2009: 256) mengatakan, mengapa pembelajaran begitu penting? Hal ini karena memiliki pengaruh yang berarti pada pengambilan keputusan uang menunjukkan proses membangun dan memilih dari seperangkat alternatif untuk memecahkan masalah (why is learning so important?. Because it has a significant impact on decision making, which refers to the process of generating and choosing from a set of alternatives to solve a problem). Pembinaan merupakan pembekalan bagi kepala sekolah dalam melakukan tugas dan tanggung jawabnya. Dalam pembekalan ini akan meningkatkan pengetahuan pengambilan keputusan yang tepat, cepat, dan rasional. Hal ini sebagaimana menurut John M. Ivancevich (2007: 399) mengatakan satu cara memperlihatkan arti latihan dan pembinaan menyeluruh adalah menggunakan model gambar bagaimana pem-binaan terbuka dalam suatu organisasi. Tahapan pelayanan membutuhkan penilaianseperti rumusan keputusan yang terus dibuat pada tahap berikutnya (One way to display the meaning and comprehensiveness of training is to use a visual model of how it unfold in on organization. The needs assesment phase serves as the formulation for decisions that must be made at later phases). Pelaksanaan pembinaan membuka kesempatan bagi pekerja lainnya. Artinya tidak ada diskriminasi bagai pekerja dalam upaya mencapai tujuan organisasi.

Dengan demikian didugapembinaan berpengaruh langsung positif terhadap pengambilan keputusan.

\section{Pembinaan dan Komunikasi Interpersonal}

Secara umum komunikasi adalah proses sosial yang berlangsung antar manusia. Proses merupakan suatu tahapan kegiatan tindakan dan peristiwa selama beberapa waktu menuju hasil tertentu. Tahapan dimulai dari pesan yang diciptakan sampai timbulnya pengaruh dan perubahan pada sasaran.

Kemampuan berkomunikasi antar individu merupakan salah satu ciri kecerdasan intelektual dan kecerdasan emosional yang dapat memberikan pemahaman, maksud dan tujuan dalam organisasi. 
Menurut John M. Ivancevich (2007 :427) mengatakan, pimpinanharus berkomunikasi bahwa dia atau is sedang membuat suatu komitmen untuk mencapai mutu terpadu dalam setiap penyelesaian pencapaian dalam organisasi. Pimpinan harus komit mendirikan suatu program perluasan komunikasi yang melibatkan manajer dan pekerja (the chief executif officer must communicate that he or she is making a commitment to achieve total quality in everything that's done the organization. The CEO must be committed to establishing a companywide communication program that involves manager and workers). Bagi anggota organisasi, tidak terlepas dari komunikasi,karena apabila tidak ada komunikasi maka pekerjaan tidak dapat berjalan dengan baik.Dengan demikian dapat diduga pembinaan berpengaruh langsung terhadap komunikasi interpesonal.

\section{Pengetahuan Manajerial dan}

Pengambilan Keputusan.

Bagi setiap manajer akan mempelajari bagaimana menerapkan penjabaran instruksi manajer yang lebih tinggi tingkatnya. Dalam pengambilan keputusan ini, manajer harus memiliki pengetahuan manajerial sehingga memiliki kemampuan untuk melakukan pengambilan keputusan yang baik. Tidak jarang organisasi tidak mencapai tujuan karena kesalahan dalam pengambilan keputusan.

Kepala sekolah sebagai pemimpin diharapkan memiliki pengetahuan atas bawahan, sebagaimana menurut Jerald Greenberg, Robert A. Saron (2008: 388) mengatakan, keputusan yang berhubungan keputusan organisasi dipengaruhi oleh banyak faktor dihubungkan dengan tiga tingkat analisis di dalam lapangan perilaku organisasi individu, kelompok dan organisasi (organizational decisions are affected by all factors associated with three levels of analysis in the field of organizational behavior- individuals, groups, and organizations). Kepala sekolah sebagai manajer dalam pengambilan keputusan terlebih dahulu memahami perilaku individu, kelompok dan organisasi.

Dengan demikian dapat diduga bahwa pengetahuan manajerial berpengaruh langsung terhadap pengambilan keputusan.

4. Pengetahuan Manajerial dan Komunikasi Interpersonal

Tidak dapat dipungkiri pengetahuan yang beragam selalu mengalami perubahan dalam ilmu pengetahuan dan teknologi (iptek). Pengalaman manusia berubah menjadi pengetahuan yang mengakibatkan bertambahnya ilmu pengetahuan. Pengetahuan dipergunakan dalam mengelola organisasi balk yang berskala kecil maupunbesar. Atas pengetahuan seseorang, maka dia akan memiliki kemampuan untuk menggerakkan, membimbing, membina, mengarah kan bawahan dalam melakukan tugas dan tanggung jawab masing-masing.

Pelaksanaan tugas yang beragam dilaksanakan kepala sekolah diharapkan dapat mencapai tujuan organisasi.

Menurut Jennifer M. George dan Garreth R. Jones (2005: 438) mengatakan, (demikian juga, pekerja-pekerja dimotivasi melaksanakan pada tingkat yang berat, bilamana seorang mengkomunikasikan secara jelas apa yang diharapkan darinya dan meng- ungkapkan dengan yakin dalam kemampuan mereka untuk melaksanakan. (Likewise, employees are motivated to perform at a high level when someone communicates clearly what is expected of them and expresses confidence in their ability to perform). Bagi setiap manajer dimasingmasing tingkat, menerapkan penjabaran atasan secara terus-menerus. Penerapan penjabaran dilakukan melalui komunikasi terhadap bawahan. Komunikasi juga dilakukan di antara sesama manajer dan juga terhadap atasannya. Penerapan 
komunikasi interpersonal yaitu antara manajer dan bawahan, dalam bentuk instruksi. Untuk dapat memahami maknanya, diharapkan komunikasi dilaksanakan dengan tepat.Misalnya harus jelas, sehingga makna instruksi itu jelas bagi bawahan.Bagi seorang manajer juga diharapkan memahami bawahannya bagaimana kemampuannya dalam hal berkomunikasi.

Pelaksanaan tugas akan berjalan sesuai dengan apa yang diharapkan apabila bawahan dapat dengan tepat memahami instruksi. Bagi manajer diperlukan melakukan pengawasan apakah tugas sudah sesuai dengan instruksi.

Dengan demikian dapat diduga bahwa pengetahuan manajerial berpengaruh langsung terhadap komunikasi interpesonal.

5. Komunikasi Interpersonal dan Pengambilan Keputusan

Menurut Jennifer M. George dan Gareth R. Jones (2005: 471) mengatakan dan suatu tujuan organisasi mendapat keuntungan terancam bilamana pengalaman-pengalaman tim manajemen puncak mengalami, masalah-masalah komunikasi. Melalui proses pengambilan keputusan, anggota-anggota organisasi memilih bagaimana menanggapi masalahmasalah ini dan yang lain (And an organization's goal is Threatned when the topmanagement team experiences comunication problems. Through the decision - making process, organizational members choose how to respond to these and other kinds of problems). Dalam hal berkomunikasi, para anggota organisasi juga akan mengambil keputusan bagaimana agar komunikasi balk pemberi dan penerima informasi sating dapat memahamiterhadap Kinerja,

\section{Hipotesis penelitian}

1. Terdapat pengaruh langsung positif Pembinaan terhadap Pengambilan
Keputusan.

2. Terdapat pengaruh langsung positif Pembinaan terhadap Komunikasi Interpersonal.

3. Terdapat pengaruh langsung positif Pengetahuan Manajerial terhadap Pengambilan Keputusan.

4. Terdapat pengaruh langsungpositif Pengetahuan Manajerialterhadap Komunikasi Interpersonal.

5. Terdapat pengaruh langsung positif Komunikasi Interpersonal terhadap Pengambilan Keputusan.

\section{Metodologi Penelitian}

Tujuan Penelitian

Secara operasional tujuanpenelitianini adalah untuk mengkaji, menganalisis dan mengungkapkan pengaruh Pembinaan, Pengetahuan Manajerial, dan Komunikasi Interpersonal terhadap Pengambilan Keputusan.

\section{Metode Penelitian}

Penelitian ini menggunakan pendekatan studi kausal yaitu sistem aliran ke satu arah. Pendekatan kuasal merupakan analisis ada atau tidak ada pengaruh antara satu variabel dengan variabel lainnya dengan menggunakan teknik analisis jalur (path analysis).

Waktu dan tempat penelitian

Penelitian ini dilaksanakan mulai bulan Oktober 2012 sampai bulan Juni 2013. Penelitian ini dilaksanakan di Kota Jakarta Utara, DKI Jakarta. Model penelitian seperti gambar di bawah ini

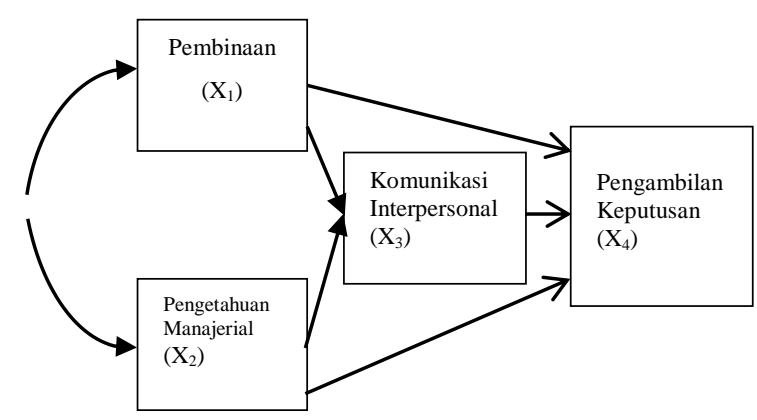




\section{Gambar}

Pengaruh Kausal X1, X2, X3, X4

Keterangan:

$\mathrm{X} 1=$ Pembinaan

$\mathrm{X} 2=$ Pengetahuan Manajerial

$\mathrm{X} 3=$ Komunikasi Interpesonal

$\mathrm{X} 4=$ Pengambilan Keputusa

\section{Hasil Penelitian}

Deskripsi Data

Dari hasil penelitian, terlebih dahulu dideskripsikan dengan Maksud untuk memberikan gambaran umum mengenai distribusi data yang merupakan olahan dari data mentah (row datum) dengan menggunakanteknikstatistikdeskriptif.

Gambaran umum ini berupa jumlah responder, butir soal, skor, harga skor, rata-rata, simpangan baku, modus, median, skor maksimum, skor minimum, distribusi frekuensi, varians dan histogram.

Masing-masing variabel yang terdiri dari Pembinaan (X1), Pengetahuan Manajerial (X2), Komunikasi Interpersonal (X3) dan Pengambilan Keputusan (X4) disajikan pada tabel di bawah

Tabel Deskriptif Statistik

\begin{tabular}{|c|l|r|r|r|r|}
\hline No & STATISTIK & \multicolumn{1}{|c|}{$\mathrm{X}_{1}$} & \multicolumn{1}{c|}{$\mathrm{X}_{2}$} & \multicolumn{1}{c|}{$\mathrm{X}_{3}$} & \multicolumn{1}{c|}{$\mathrm{X}_{4}$} \\
\hline 1 & $\mathrm{n}$ & 40 & 40 & 70 & 40 \\
\hline 2 & $\begin{array}{l}\text { Skor } \\
\text { Terendah }\end{array}$ & 78 & 75 & 79 & 78 \\
\hline 3 & $\begin{array}{l}\text { Skor } \\
\text { Tertinggi }\end{array}$ & 117 & 120 & 118 & 118 \\
\hline 4 & $\begin{array}{l}\text { Rentang } \\
\text { Skor }\end{array}$ & 39 & 45 & 39 & 40 \\
\hline 5 & Mean & 100,35 & 98,63 & 100,78 & 101,58 \\
\hline 6 & Median & 101 & 100 & 100,50 & 102,50 \\
\hline 7 & Modus & 99 & 100 & 113 & 99 \\
\hline 8 & $\begin{array}{l}\text { Standard } \\
\text { Deviasi }\end{array}$ & 9,755 & 9,740 & 11,147 & 12,453 \\
\hline 9 & Varians & 95,156 & 94,855 & 124,256 & 155,071 \\
\hline 10 & Skor Total & 4041 & 3945 & 4031 & 4063 \\
\hline 11 & Butir Soal & 30 & 30 & 30 & 30 \\
\hline 12 & $\begin{array}{l}\text { Butir yang } \\
\text { Valid }\end{array}$ & 27 & 27 & 28 & 28 \\
\hline 13 & $\begin{array}{l}\text { Panjang } \\
\text { Kelas }\end{array}$ & 6 & 5 & 6 & 6 \\
\hline No & STATISTIK & $\mathrm{X}_{1}$ & $\mathrm{X}_{2}$ & $\mathrm{X}_{3}$ & $\mathrm{X}_{4}$ \\
\hline
\end{tabular}

\section{Pengujian Persyaratan Analisis}

\section{Uji Normalitas}

Tabel Rangkuman Hasil Pengujian Galat Baku Taksiran

\begin{tabular}{|c|c|c|c|c|}
\hline No. & $\begin{array}{c}\text { Galat Baku Taksiran } Y \\
\text { atas } X 1, X 2 \text {, dan } Y \text { atas } \\
X 1, X 2 \text { dan } X 3\end{array}$ & $\begin{array}{l}\text { Nilai } \\
\text { L hitung }\end{array}$ & $\begin{array}{l}\text { Nilai } \\
\text { L tabel a } \\
0,05\end{array}$ & Kesimpulan \\
\hline 1. & $\hat{X}_{3}=49,60+0,51 X_{1}$ & 0,0840 & 0,1195 & Normal \\
\hline 2. & $\widehat{X}_{3}=55,41+0,46 X_{2}$ & 0,0894 & 0,1195 & Normal \\
\hline 3. & $\hat{X}_{4}=43,38+0,58 X_{1}$ & 0,0962 & 0,1195 & Normal \\
\hline 4. & $\hat{X}_{4}=50,29+0,52 X_{2}$ & 0,0889 & 0,1195 & Normal \\
\hline 5. & $\hat{X}_{4}=57,24+0,44 X_{3}$ & 010930 & 0,1195 & Normal \\
\hline
\end{tabular}

Dari seluruh perhitungan normalitas Galat baku Taksiran $\mathrm{Y}$ atas $\mathrm{X}_{1}, \mathrm{X}_{2}$, dan $\mathrm{Y}$ atas $\mathrm{X}_{1}, \mathrm{X}_{2}, \mathrm{X}_{3}$ seperti rangkuman di atas, menunjukkan nilai L hitung <dari L tabel, maka perhitungan seterusnya dapat dilanjutkan.

2. Uji Signifikansi dan Linearitas atas pengaruh langsung dari setiap variabel dengan melakukan perhitungan Analysis of Varians (ANAVA) yang merupakan prasyarat untuk perhitungan selanjutnya. dari:

Pengaruh setiap variabel yang terdiri

a. Pengaruh Komunikasi Interpersonal $\left(\mathrm{X}_{3}\right)$ atas Pembinaan $\left(\mathrm{X}_{1}\right)$.

b. Pengaruh Komunikasi Interpersonal (X3) atas Pengetahuan Manajerial (X2).

c. Pengaruh Pengambilan Keputusan (X4) atas Pembinaan (X1).

d. Pengaruh Pengambilan Keputusan (X4) atas Pengetahuan Manajerial (X2).

e. Pengaruh Pengambilan Keputusan (X4) atas Pembinaan (X1).

f. Pengaruh Pengambilan Keputusan (X4) atas Pengetahuan Manajerial (X2).

g. Pengaruh Pengambilan Keputusan Kepala Sekolah $\left(X_{4}\right)$ atas Komunikasi Interpersonal Penjaminan $\left(\mathrm{X}_{3}\right)$. Salah satu pengujian Signifikansi dan Linearitas "Pengaruh Komunikasi Interpersonal $\left(\mathrm{X}_{\mathbf{3}}\right)$ atas Pembinaan $\left(\mathrm{X}_{1}\right)$ "seperti tabel di bawah ini: 
Tabel 14: ANAVA Signifikasidan Linearitas Regresi Sederhana $\widehat{X}_{3}=49,60+$ $0,51 \mathrm{X}_{1}$

\begin{tabular}{|c|c|c|c|c|c|c|}
\hline $\begin{array}{c}\text { Sumber } \\
\text { Varians }\end{array}$ & $\mathrm{dk}$ & JK & RJK & Fhitung & Ftabel & $\begin{array}{c}\text { Sumber } \\
\text { Varians }\end{array}$ \\
\hline Total & 40 & 411.077 & 411.077 & & $0=0,05$ & \\
\hline $\begin{array}{c}\text { Koefisien } \\
\text { (a) }\end{array}$ & 1 & $406.224,03$ & $406.224,03$ & & & $\begin{array}{c}\text { Koefisien } \\
(\mathrm{a})\end{array}$ \\
\hline $\begin{array}{c}\text { Regresi } \\
\text { (b/a) }\end{array}$ & 1 & 974,64 & 974,64 & $9,57^{\star *}$ & 4,10 & $\begin{array}{c}\text { Regresi } \\
\text { (b/a) }\end{array}$ \\
\hline Sisa & 38 & $3.874,33$ & 101,96 & & & Sisa \\
\hline
\end{tabular}

Keterangan:

$\mathrm{db}=$ derajat kebebasan

$\mathrm{JK}=$ Jumlah Kuadrat

RJK = Rata-rata Jumlah Kuadrat

Berdasarkan tabel pengujian signifikansi dan pengujian linearitas, maka dapat disimpulkan bahwa persamaan regresi $X 3=49,60+0,51 \mathrm{X} 1$, regresi sangat signifikan dengan pengujian $\mathrm{F}$ hitung $9,56>$ dari $\mathrm{F}$ tabel $\mathrm{a}=0,05(4,10)$ dan $a=0,01(7,35)$ dan regresi berbentuk linear dengan pengujian $\mathrm{F}$ hitung $0,57<$ dari $\mathrm{F}$ tabel $\mathrm{a}=0,05(2,57)$ dan $\mathrm{a}=0,01$ $(3,94)$. Persamaan regresi dapat memberi gambaran bahwa setiap peningkatan satu skor pembinaan akan diikuti oleh kenaikan komunikasi interpersonal sebesar 0,51 pada konstanta 49,60.

\section{Uji Hipotesis}

Dari olahan SPSS diperoleh koefisien jalur dari setiap diagram sebagaimana hasil ditampilkan seperti pada tabel rangkuman di bawah ini:

Tabel Rangkuman Hasil Perhitungan

Koefisien Jalur

\begin{tabular}{|c|c|c|c|c|}
\hline No. & $\begin{array}{c}\text { Koefisien } \\
\text { Jalur }\end{array}$ & $\mathbf{t}$ hitung & $\begin{array}{c}\mathbf{t} \text { tabel } \\
(\mathbf{\alpha} \mathbf{0 , 0 5})\end{array}$ & Kesimpulan \\
\hline 1 & $\mathrm{p}_{41}=0,297$ & 1,883 & 1,684 & $\begin{array}{c}\text { Jalur } \\
\text { berarti }\end{array}$ \\
\hline 2 & $\mathrm{p}_{31}=0,543$ & 4,183 & 1,684 & $\begin{array}{c}\text { Jalur } \\
\text { berarti }\end{array}$ \\
\hline 3 & $\mathrm{p}_{42}=0,380$ & 2,466 & 1,684 & $\begin{array}{c}\text { Jalur } \\
\text { berarti }\end{array}$ \\
\hline 4 & $\mathrm{p}_{32}=0,457$ & 3,525 & 1,684 & Jalur \\
\hline
\end{tabular}

\begin{tabular}{|c|c|c|c|c|}
\hline & & & & berarti \\
\hline 5 & $p_{43}=0,323$ & 1,963 & 1,684 & $\begin{array}{c}\text { Jalur } \\
\text { berarti }\end{array}$ \\
\hline
\end{tabular}

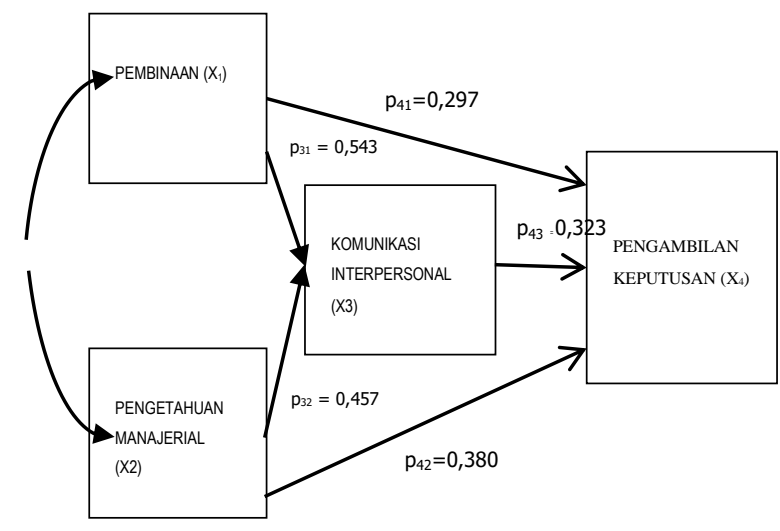

Gambar Hipotetik

Gambar Pengaruh Kausal X1, X2, X3, X4

Keterangan :

$\mathrm{X} 1=$ Pembinaan

$\mathrm{X} 2=$ Pengetahuan Manajerial

$\mathrm{X} 3=$ Komunikasi Interpesonal

$\mathrm{X} 4=$ Pengambilan Keputusan

Tabel Rangkuman Pengujian Hipotesis

\begin{tabular}{|c|c|c|c|c|c|}
\hline No & Hipotesis & Uji Statistik & $\begin{array}{c}\text { Koefisien } \\
\text { Jalur }\end{array}$ & $\begin{array}{l}\text { Thitung } \\
\mathrm{Db}=38\end{array}$ & Keputusan \\
\hline 1 & $\begin{array}{l}\text { Pembinaan (X1) } \\
\text { berpengaruh } \\
\text { langsung positif } \\
\text { terhadap } \\
\text { pengambilan } \\
\text { keputusan Kepala } \\
\text { Sekolah (X4) }\end{array}$ & $\begin{array}{l}\mathrm{H}_{0}: \beta_{41}<0 \\
\mathrm{H} 1: \beta 41>0\end{array}$ & $p 41=0,297$ & 1,833 & $\begin{array}{l}\text { H0 ditolak } \\
\text { Ha diterima }\end{array}$ \\
\hline 2 & $\begin{array}{l}\text { Pembinaan (X1) } \\
\text { berpengaruh } \\
\text { langsung positif } \\
\text { terhadap } \\
\text { komunikasi } \\
\text { interpersonal } \\
\text { kepala sekolah } \\
\text { (X3) }\end{array}$ & $\begin{array}{l}H_{0}: \\
\beta_{31} \leq 0 \\
H_{1}: \\
\beta_{31}>0\end{array}$ & $\begin{array}{l}P_{31}= \\
0,543\end{array}$ & 4,183 & $\begin{array}{l}\mathrm{H}_{0} \text { ditolak } \\
\mathrm{H}_{1} \\
\text { diterima }\end{array}$ \\
\hline 3 & $\begin{array}{l}\text { Pengetahuan } \\
\text { Manajerial (X2) } \\
\text { berpengaruh } \\
\text { langsung positif } \\
\text { terhadap } \\
\text { pengambilan } \\
\text { keputusan kepala } \\
\text { sekolah (X4) } \\
\end{array}$ & $\begin{array}{l}\mathrm{H}_{0}: \\
\beta_{42} \leq 0 \\
\mathrm{H}_{1}: \\
\beta_{42}>0\end{array}$ & $\begin{array}{l}p_{42}= \\
0,380\end{array}$ & 2,466 & $\begin{array}{l}\mathrm{H}_{0} \text { ditolak } \\
\mathrm{H}_{1} \\
\text { diterima }\end{array}$ \\
\hline 4 & $\begin{array}{l}\text { Pengetahuan } \\
\text { Manajerial (X2) } \\
\text { berpengaruh } \\
\text { langsung positif } \\
\text { terhadap } \\
\text { komunikasi } \\
\text { interpersonal } \\
\text { kepala sekolah } \\
\text { (X3) }\end{array}$ & $\begin{array}{l}\mathrm{H}_{0}: \\
\beta_{32} \leq 0 \\
\mathrm{H}_{1}: \\
\beta_{32}>0\end{array}$ & $\begin{array}{l}P_{32}= \\
0,457\end{array}$ & 3,525 & $\begin{array}{l}\mathrm{H}_{0} \text { ditolak } \\
\mathrm{H}_{1} \\
\text { diterima }\end{array}$ \\
\hline 5 & $\begin{array}{l}\text { Komunikasi } \\
\text { interpersonal (X3) } \\
\text { berpengaruh } \\
\text { langsung positif } \\
\text { terhadap }\end{array}$ & $\begin{array}{l}\mathrm{H}_{0}: \\
\beta_{43} \leq 0 \\
\mathrm{H}_{1}: \\
\beta_{43}>0\end{array}$ & $\begin{array}{l}p_{43}= \\
0,323\end{array}$ & 1,963 & $\begin{array}{l}\mathrm{H}_{0} \text { ditolak } \\
\mathrm{H}_{1} \\
\text { diterima }\end{array}$ \\
\hline
\end{tabular}




\begin{tabular}{|l|l|l|l|l|}
\hline $\begin{array}{l}\text { pengambilan } \\
\text { keputusan kepala } \\
\text { sekolah (X4) }\end{array}$ & & & & \\
\hline
\end{tabular}

Tabel Rangkuman Pengaruh langsung dan tidak langsung Variabel Pembinaan (X1), Pengetahuan Manajerial (X2), Komunikasi Interpersonal (X3), dan Pengambilan Keputusan Kepala Sekolah (X4)

\begin{tabular}{|l|c|c|c|}
\hline \multirow{2}{*}{ Variabel } & \multicolumn{2}{|c|}{ Pengaruh } & \multirow{2}{*}{$\begin{array}{c}\text { Total } \\
\text { Pengaruh }\end{array}$} \\
\cline { 2 - 3 } & $\begin{array}{c}\text { Langsung } \\
\text { Terhadap } \\
\text { pengambilan } \\
\text { keputusan }\end{array}$ & $\begin{array}{c}\text { Tidak } \\
\text { langsung } \\
\text { melalui } \\
\text { interpersonal }\end{array}$ & \\
\hline $\begin{array}{l}\text { Pembinaan } \\
\left(X_{1}\right)\end{array}$ & 0,297 & 0,175 & 0,472 \\
\hline $\begin{array}{l}\text { Pengetahuan } \\
\text { Manajerial } \\
\left(X_{2}\right)\end{array}$ & 0,323 & 0,148 & 0,471 \\
\hline
\end{tabular}

\section{Pembahasan}

Untuk mengetahui upaya ini, peneliti melakukan penelitian pada tingkat Sekolah Dasar (SD) Negeri di Kecamatan Tanjung Periok, Kota Jakarta Utara, Daerah Khusus lbukota (DKI) Jakarta. Peningkatan kualitas pendidikan tidak dapat dilaksanakan dalam waktu yang singkat karena membutuhkan proses, sarana dan prasarana, biaya, sumber daya manusia. Oleh sebab itu setiap langkah dalam penyelenggaraan pendidikan selalu mendapat tantangan. Dalam penyelenggaraan pendidikan, maka atas hasil penelitian di bawah ini dibahas bagaimana jalan keluar dalam mengatasi tantangan yang dihadapi. Berdasarkan hasil penelitian bahwa setiap satu unit pembinaan mengakibatkan peningkatan pengambilan keputusan kepala sekolah 0,58. Dari hasil penelitian sesuai pendapat Jerald Greenberg, Robert A. Baron (2008) bahwa dalam pengambilan keputusan merupakan memilih alternatif. Dalam memilih alternatif membutuhkan pembinaan. Hasil penelitian menunjukkan terdapat pengaruh antara pembinaan dengan pengambilan keputusan dengan koefisien jalur sebesar 0,297. Nilai ini perlu ditingkatkan dengan berbagai bentuk pendidikan dan latihan (diktat) agar pengambilan keputusan kepala sekolah semakin baik. Teori mendukung peneliti dalam mewujudkan definisi konseptual, definisi operasional, indikator dan menyusun instrumen penelitian. Pembinaan mengakibatkan setiap satu unit akan meningkatkan komunikasi interpersonal sebesar 0,51. Dalam penelitian, koefisien jalur sebesar 0,543 diperlukan peningkatan pembinaan yang akan meningkatkan komunikasi interpersonal. Pembinaan merupakan pemberdayaan sumber daya manusia sesuai dengan kemampuan, keahlian, keterampilan Robert M. Fulmer (2002). Teori ini mendukung peneliti dalam pembuatan instrumen.

Pengetahuan Manajerial merupakan kemampuan pengetahuan (cognitive ability), kemampuan emosi (emotional ability), dan kemampuan pisik (phisical ability). Menurut Fleishman, E.A," dalam Jason A. Colquitt, Jeffery A. Lepine, Michael J. Wesson (2009). Dari hasil penelitian setiap satu unit pengetahuan manajerial akan meningkatkan komunikasi interpersonal sebesar 0,46. Koefisien jalur menunjukkan nilai sebesar 0,457, jalur tidak putus, terdapatpengaruh pengetahuan manajerial terhadap komunikasi interpersonal. Teori ini mendukungpenelitidalampembuataninstru men.

Pengetahuan manajerial merupakan kemampuan berkenaan dengan pengetahuan pengikut-pengikut, pengalaman, dan keahlian kemampuan melengkapi keberhasilan tugas khusus menurut Paul Hersey, Kenneth $\mathrm{H}$. Blanchard, Dewey E. Johnson (2008). Peningkatan satu unitpengetahuan manajerial akan meningkatkan pengambilan keputusan sebesar 0,52. Koefisien jalur menunjukkan nilai sebesar 0,380, jalur tidak putus. Perolehan nilai diperlukan peningkatan pengetahuan manajerial untuk meningkatkan pengambilan keputusan yang baik. 
Peningkatan komunikasi interpersonal satu unit akan meningkatkan pengambilan keputusan sebesar 0,44.

Komunikasi interpersonal merupakan proses psikologis yang menjadi dasar perubahan tingkah laku dan penekanan utamanya pada transfer informasi dari satu orang ke oranglainnya. MenurutLuthans(1998) Transfer informasi merupakan sesuai yang sudah diputuskan untuk dilaksanakan.

Dalam mentransfer informasi membutuhkan tingkat pengambilan keputusan yang baik. Dengan demikian teori yang ada mendukung peneliti. Koefisien jalur sebesar 0,323, jalur tidak terputus. Dengan komunikasi interpersonal yang baik akan mendukung pengambilan keputusan yang baik. Teori ini mendukung peneliti.

Peneliti melakukan upaya untuk menghindarkan berbagai kelemahan, akan tetapi terdapat hal-hal yang tidakdapat dikendalikan. Penelitian ini menggunakan metode kuantitatif dengan pembuktian pengujian statistik berdasarkan teoriterhadap variabel-variabel yang diteliti. Mengingat berbagai aspek dalam variabel yang diteliti terdapat hal-ha I yang tidakdapat didekatisecara kuantitatif. Pendekatan dengan metode kuantitatif tidak dapat menggali informasi secara mendalam, sehingga hasil akhir yang diperoleh menimbulkan banyak kelemahan.

Tahap pengumpulan data, peneliti terlebih dahulu melakukan ujicoba instrumen dengan menyebarkan kuesioner. Kelemahan yang didapat, responder tidak secara keseluruhan mencermati dengan benar pernyataanpernyataan dan pertanyaan-pertanyaan yang ada. Hal ini disebabkan persepsi pengetahuan dan latar belakang yangberbeda dan akan mempengaruhi terhadap hasil pengujian pengolahan data.Peneliti berusaha dengan cermat untuk mengetahui kelemahan-kelemahan dalam meningkatkan kualitas sumber daya manusia terutama pada sekolah dasar yang merupakan landasan untuk pendidikan lanjutan yang menjadi modal dalam membangun daerah kota Jakarta Utara.

Hasil yang diperoleh dengan berbagai kelemahan dan keterbatasan memberikan wawasan bare bagi peneliti, untuk dijadikan modal ke depan dalam melakukan penelitian. Sebagai ilmu sosial yang cepat mengalami perubahanperubahan terutama ilmu pengetahuan dan teknologi (iptek) berkembang dengan pesat, arus informasi dan globlalisasi sehingga apa yang diperoleh pada kemungkinanterdapatperbedaa

kesimpulan apabila dilakukan penelitian oleh peneliti yang lain pada obyek yang sama.

\section{Kesimpulan, Implikasi, dan Saran \\ Kesimpulan}

Hasil akhir dari seluruh data penelitian ini merupakan kesimpulan, implikasi clan saran. Perolehan data kemudian dianalisis mulaidari ujicoba instrumen berupa validitas dan reliabilitas.Data dihimpun clan ditabulasikan, kemudian dideskripsikan berupa penyajian skor total, skor tertinggi, skor terendah, rentang skor, mean, modus, frekuensi distribusi, histrogramdan grafik. Selanjutnya dilakukan pengujian galat baku taksiran sebagai prasyarat apakah populasi berdistribusi normal. Prasyaratselanjutnya yaitu pengujian signifikansi dan linearitas regresi sederhana. Setelah memenuhi persyaratan-persyarat tersebut, maka perhitungan dapatdilanjutkan untuk mengetahui pengaruh besarnya koefisien jalur dengan melakukan analisis jalur (path analysis).

Dari penelitian ini peneliti memperoleh temuan sebagai berikut:

1. Terdapat pengaruh langsung positif pengetahuan manajerial terhadap pengambilan keputusan kepala sekolah artinya peningkatan pengetahuan manajerial, akan 
memperbaiki pengambilan keputusan kepala sekolah.

2. Terdapat pengaruh langsung positif komunikasi interpersonal terhadap pengambilan keputusan kepala sekolah, artinya semakin baik komunikasi interpersonal, maka akan lebih baik pengambilan keputusan yang dibuat kepala sekolah.

3. Terdapat pengaruh langsung positif pembinaan terhadap komunikasi interpersonal, artinya dengan meningkatnya pembinaan, akan semakin baik komunikasi interpersonal yang dilakukan oleh kepala sekolah.

4. Terdapat pengaruh langsung positif pengetahuan manajerial terhadap komunikasi interpersonal, artinya dengan bertambah pengetahuan manajerial, maka semakin baik komunikasi interpersonal yang dilakukan kepala sekolah.

5. Terdapat pengaruh langsung positif pembinaan terhadap pengambilan keputusan artinya makin sering melakukan pembinaan, maka makin baik pengambilan keputusan kepala sekolah.

\section{Implikasi}

1. Jika pengetahuan manajerial merupakan upaya untuk mengelola, menggerakkan, mengarahkan, dan membimbing bawahan agar mau melaksanakan tugas dan tanggung jawabnya dengan baik, maka pengetahuan manajerial kepala sekolah ditingkatkan dengan cara,seminar, pendidikan,pelatihan, dan kualifikasi pendidikan sehingga kepala sekolah dapat lebih baik dalam pengambilan keputusan.

2. Jika komunikasi interpersonal ditingkatkan dengan jelas, cepat, tepat maka pengambilan keputusan kepala sekolah akan lebih baik.

3. Jika pembinaan secara berkesinambungan sesuai dengan visi dan misi pendidikan, maka komunikasi interpersonal kepala sekolah akan lebih baik.

4. Jika pengetahuan manajerial merupakan kewenangan untuk menggerakkan, mengarahkan bawahan dalam melaksanakan tugas dan tanggung jawab, maka pengetahuan manajerial dapat di pahami sehingga kegiatan komunikasi interpersonal dapat berjalan secara efisien dan efektif.

5. Jika pembinaan merupakan wujud dalam meningkatkan pengambilan keputusan, maka kepala sekolah dapat memilih alternatif pengambilan keputusan yang lebih baik.

\section{Saran}

Hasil penelitian menyimpulkan terdapat kelebihan dan kekurangan kepala sekolah,makauntukperbaikan-perbaikan itu peneliti memberikan saran-saran sebagai berikut:

1. Agar terhadap kepala sekolah dilakukan pembinaan yang menyangkutpengelolaansekolahsecar aberkesinambungan oleh pengawas dengan instansi terkait sebagai bekal dalam upaya meningkatkan kualitas pendidikan .

2. Kepala Sekolah menanamkan yang berhubungan dengan pengelolaan sekolah dengan melibatkan tenaga pendidikan dan kependidikan memahami, menghayati, artinya komunikasi interpersonal.

3. Kepala Sekolah proaktif mengantisipasi serta menyerap kebijakan pimpinan sebagai atasanlangsungdalammenerapkan pengetahuanmanajerial untukdapatmelaksanakankomunikasi interpersonal yang baik guna mencapai tujuan pendidikan.

4. Kepala sekolah meningkatkan pengetahuan secara teoritis, misalnya mengikuti penataran, seminar, workshop agar dapat memahami 
teknik-teknik manajerial sekolah.

5. Kepala Sekolah diharapkan mampu mengevaluasi, menilai, menganalisis serta mengatasi kesulitan individu untuk dapat memilih alternatif yang terbaik dalam rangka meningkatkan pengambilan keputusan kepala sekolah yang cepat, tepat, rasional dan realistic

\section{Daftar Pustaka}

AECT. 1986 definisi Teknologi Pendidikan Satuan Tugas Definisi dan Teknologi, Jakarta: Pusat antar Universitas Terbuka bekerjasama dengan Rajawali, 1986.

Ametembun, N., A., Supervise Pendidikan: Penuntun bagi para Pembina Pendidikan Kepala Sekolah dan Guru-Guru, Bandung: FKIP IKIP Bandung, 1975.

Arikunto, Suharsini, Organisasidan AdministrasiPendidikan Teknologi dan Kejuruan, Jakarta: Depdikbud Ditjen Dikti, 1988.

Brumbauhg, Robert S., Nathniel, M., Lawrence Philosopers on Education Six Essay on the Foundation of Western Thought, Boston, Hought on Miffin Company,-1963

Colquitt, Jason A., A. Lepine, MichaelJ.Wesson,OrganizationalB ehavior:

Improving Performance andCommitment in the Workplace, New York: McGraw-Hill Irwin, 2009.

Djaali, Puji Mulyono, dan Ramly, Pengukuran Dalam BidangPendidikan, Jakarta:Progra m Pascasarjana Universitas Negeri Jakarta, 2000.

Delors, Jacques Belajar: Harty Karun Di Dalamnya, Terjemahan W.P. Napitupulu Paris: UNESCO/ Komisi Nasional Indonesia untuk Unesco, 1996.
Effendi, Uchajana, Onong, 11mu Komunikasi, Teori dan Praktek, Bandung: RamajaRosdakarya, 2001.

Fulmer, Robert M., The Corporate University Handbook: Designing Managing and Growing a Successful) Program, Mark Allen Editor, New York: Amacom, 2002

Gatewood, Robert D. Robert R, Taylor, O.0Ferrel,

ManagementComprehension Analysis and Application, Chicago IL: Richard D. Irwin Inc., 1995.

George, M., Garreth R. Jones, OrganizationalBehavior: UnderstandingandManaging, Upper Saddle River, New Jersey: Pearson Prentice Hall, 2005.

Gibson,JamesL., John M. Ivan cevich, Organisasi, terjemahan Nunuk Adiarni, Jakarta: Bina Aksara, 1977.

Gibson, James L., et., al., Organizations: Behavior, Structure, Processes, New York: McGraw-Hill, 2003.

Gibson, James, L., et., al., Organizations: Behavior, Structure, Processes, Twelfth Edition, New York: McGraw-Hill, 2006.

Greenberg, Jerald, Robert A. Baron, Behavior in Organizations, Ninth Edition, Upper Saddle River, New Jersey: Pearson Prentice Hall, 2008.

Gouran, S., Dennis, Larry D. Miller,and Willian E. Weithoff,Mastering Communication, Boston: Allyn and Bacon,1992.

Hanna, Michael S., Communication in Bussines and Profesional Settings, New York: McGraw-Hill, 1991.

Hersey, Paul, Kenneth H. Blanchard, DeweyE.Johnson,ManagementofO rganizational Behavior: Leading Human Resources, Ninth Edition, Upper Saddle River, New Jersey: Pearson Prentice Hall, 2008. 
Ivancevich John M., Human Resource Management, Tenth Edition, New York: McGraw Hill, 2007

James, Curtis, B., Jame Profesional Communication, New .York: Harper Collins Publisher, 1992

Jarvis, Peter,Universities andCorporate Universicites, London: Stylus Publishing Inc., 2001.

Luthan, Fred, Organizational Behavior, Bede, (New York: McGraw-Hill, Inc., 1998.

Mulyasa,E., Menjadi Guru Profesional: Menciptakan Pembelajaran Kreatif dan Menyenangkan, Bandung: PT . Remaja Rosdakarya, 2008.

Notoatmodjo:Soekidjo, Pengembangan Sumber Daya Manusia, Jakarta: PT. RinekaCipta, 1998.

Newstrom John $W$. dan Keith Davis, Organizational Behavior.- Human Behavior at work, Eleventh Edition,New York:McGrawHillIrwin, 2002.

Robbins, Stephen P., Timothy A. Judge, Organizational Behavior, Nineth Edition, Upper Saddle River, New Jersey: Pearson Prentice Hall, 2007.

Rui, Leslie W., Llyoyd L. Byars, Supervise Key Link to Productivity, Irwin: Time Mirror Books, 1996.

Salusu, J., Pengambilan Keputusan Stratejik: Untuk Organisasi PublikdanOrganisasiNonprofit,Jak arta: PT.Gramedia,2006.

Sastrodiningrat, Soebagio, H., Kapita Selekta: Manajemen \& Kepemimpinan, Jakarta: Ind-HillCo, 1999.

Schermerhom, John Jr.,R., Manajemen, Buku 2 Edisi Bahasa Indonesia, Yogyakarta: Andi, 1998.

Seiler, Willian J., Introduction to Speech Communication, New York: Herper Collins Publisher, 1992.
Siagian, Sondang P., Filsafat Administrasi, Jakarta: PT. Toko Gunung Agung, 1995.

Stoner, James, A.F., R., Edward, Freeman, Management, New Jersey: Prentice-Hall., Inc., 1992

Sudjana, Teknik Analisis, Regresidan Korelasi, bagi parapeneliti, Bandung, Transito,1983.

Sugiyono, Metode Penelitian Administrasi, Bandung: CV. Alfabeta, 2008.

Thoha, Miftah, Perilaku Organisasi: Konsep'Dasardan Aplikasinya, Jakarta: Raja Grafindo Persada, 1995.

Pembinaan Organisasi : Proses Diagnosa \& Intervensi, Jakarta:PT.Raja Grafindo Persada, 2002.

Woolfolk, Anitah E., Education Psycology, London: Allyn\& Bacon1997 